\title{
Do mal-entendido promissor à multiplicação de vozes: considerações acerca das estratégias metodológicas para a elaboração de uma cartografia de organizações da sociedade civil
}

\section{From the promising misunderstanding to the multiplication of voices: a mapping civil society organizations} Del malentendido prometedor a la multiplicación de voces:
una cartografía de organizaciones de la sociedad civil

\author{
Rosa Maria Leite Ribeiro Pedro* \\ Universidade Federal do Rio de Janeiro - UFRJ, Rio de Janeiro, Rio de Janeiro, Brasil
}

\section{Mariana de Castro Moreira**}

AVM Faculdade Integrada, Rio de Janeiro, Rio de Janeiro, Brasil

\begin{abstract}
RESUMO
O presente artigo objetiva explorar algumas das estratégias de produção de conhecimento, a partir dos desafios e possibilidades geradas pela Teoria Ator-Rede (TAR) no campo da pesquisa em Psicologia. Tomamos como porta de entrada para tal exploração uma pesquisa por nós realizada, lançando um olhar especial para o campo dos projetos sociais como territórios de ação ou dispositivos que dão materialidade às assim chamadas Organizações da Sociedade Civil (OSC). Dois aspectos se revelaram particularmente férteis nesse processo: a noção de mal-entendido promissor (Despret, 1999) e a de cartografia de controvérsias (Latour, 2005). Concluímos apontando a potência metodológica e ontológica desses conceitos que possibilitam, por um lado, multiplicar vozes e versões e, por outro, reconhecer provisoriedade, parcialidade e incompletude de qualquer diagnóstico dos tempos atuais, além de comprometer o pesquisador com o que ele "faz existir" em sua pesquisa.
\end{abstract}

Palavras-chave: psicologia, teoria ator-rede, cartografia, controvérsias, organizações da sociedade civil.

\begin{abstract}
This paper focuses on searching some of the strategies used in knowledge production based on the challenges and opportunities created by the ActorNetwork Theory (ART) in the area of psychology research. As a starter, we have used a survey conducted by us, in which we cast a special look at the field of social projects such as the action territories that render materiality to the so-called Civil Society Organizations (CSOs). Two aspects have proved to be quite rich: the idea of the Promising Misunderstanding (DESPRET, 1999) and the Mapping Controversies (Latour, 2005). We have concluded that the methodological an ontological power of these concepts that, on one hand,
\end{abstract}


multiply voices and versions and on the other hand recognize provisionality, partiality and incompleteness of any updated diagnosis, it also compromises the researcher with what he/she "brings to exisencet" in the research.

Keywords: psychology, actor-network theory, mapping, controversies, civil society organizations.

\section{RESUMEN}

Este artículo, tratamos de retomar algunas de las estrategias de producción de conocimiento utilizadas a partir de los desafíos y posibilidades generadas por la teoría del actor-red (TAR) en el área de la investigación en Psicología. Con el fin de iniciar, se ha utilizado la investigación por nosotros, nos fijamos de manera especial en el campo de los proyectos sociales como territorios de acción en que se materializan las llamadas Organizaciones de la Sociedad Civil (OSC). Dos aspectos han demostrado ser muy ricos: la idea de la Malentendido Prometedor (Despret, 1999) y el Mapeo de Controversias (Latour, 2005). Hemos llegado a la conclusión de que una potencia metodológica y ontológica de estos conceptos que, por un lado, se multiplican las voces y versiones, y por otra parte reconocen la provisionalidad, la parcialidad y el carácter incompleto de cualquier diagnóstico actualizado, también compromete al investigador lo que él / ella "hace existir "en la investigación.

Palabras clave: psicología, teoría del actor-red, cartografía, controversias, organizaciones de la sociedad civil.

\section{I ntrodução}

Com este artigo, buscamos explorar algumas das estratégias de produção de conhecimento, a partir dos desafios e possibilidades geradas pela Teoria Ator-Rede (TAR) no campo da pesquisa em Psicologia. Tomamos como porta de entrada para tal exploração uma pesquisa por nós realizada ${ }^{1}$, cujo foco voltou-se para a atuação da sociedade civil no fortalecimento da democracia, no Brasil, nas últimas décadas. Lançamos um olhar especial para o campo dos projetos sociais como territórios de ação ou dispositivos ${ }^{2}$ que dão materialidade às assim chamadas Organizações da Sociedade Civil (OSC) e nos valemos da experiência da OSC Espaço Compartilharte uma Associação Civil para fins não-econômicos, sem fins lucrativos, que tem como foco a educação para cidadania, atuando na interface entre a Assistência Social e a Educação (Pedro \& Moreira, 2013).

Buscamos acompanhar a atuação destas organizações nos últimos quarenta anos, evidenciando o quanto elas vem se metamorfoseando e se reconfigurando de modos diversos. Nos anos 70 e 80 vemos surgir diversos movimentos sociais e organizações da sociedade civil que se mobilizam na luta contra a ditadura e pela democratização, construindo importantes conquistas que vão do silenciamento, punição e interdição à participação como conquista e direito. Já a partir das décadas de 80 e 90, participar de Organizações da Sociedade Civil abria possibilidades de ocupar o espaço público e 
ser/fazer política, entendendo-se por política não apenas uma instância ou modo de governo, mas sobretudo uma "forma de compartilhar destinos" (Nogueira, 2011, p. 250) e de reconstruir coletivamente a utopia de um futuro melhor. Hoje, há um discursomovimento de criminalização de organizações sociais, associando-as a escândalos que envolvem corrupção, política partidária e desvio de recursos públicos, de tal modo que a própria legitimidade deste trabalho e militância é colocada em xeque.

Perguntamo-nos: o que mudou, nestas práticas, a ponto de nos deslocarmos do território de possibilidades e utopias para o campo das denúncias e desvios? Acompanhar algumas destas histórias e suas recentes transformações nos pareceu decisivo para escapar das análises dicotômicas, bem como para potencializar a problematização sobre a atuação e papel da sociedade civil, hoje, fortalecendo uma agenda para as próximas décadas.

Tomamos então, os projetos sociais - dispositivos que dão materialidade às organizações da sociedade civil - como controvérsias (Latour, 1999) uma vez que entendemos que estamos lidando com um objeto polêmico, não estabilizado e permeado por relações heterogêneas, onde há conflito e disputa entre os distintos atores. Cartografar as controvérsias implica um olhar atento às práticas, que busca seguir os atores, acompanhando as discussões, incertezas e embates colocados em jogo. A sensibilidade e permanência no campo colocam-se como condições essenciais para que se possa perceber e acompanhar as configurações que se delineam e se transformam nessa viagem.

Como argumenta Venturini (2010), quando rastreamos as controvérsias, encontramo-nos onde a vida fica mais complexa, onde um conjunto mais vasto de atores está envolvido, onde as alianças e oposições se produzem e se desfazem incessantemente. Assim, quando as controvérsias se instauram, os debates se acirram e as disputas se tornam acaloradas, as entidades que compõem o social tornam-se mais visíveis (Latour, 2005).

Buscamos, portanto, nos aproximar de certas estratégias de produção de conhecimento - mais que metodologias - que se distanciam do apaziguamento e do silenciamento dos ruídos, embates e dissonâncias. O movimento é na contramão, e vai em busca de ferramentas que façam reverberar sons, multiplicar vozes.

\section{Do mal-entendido promissor à multiplicação de vozes}

Em nossa pesquisa, a ideia de mal entendido promissor (Despret, 1999) tornou-se central, reforçando a construção de um textoinvestigação tecido em busca da multiplicação de vozes e versões. Para Despret (1999, p. 328), 
o mal entendido promissor é capaz de gerar novas versões disto que o outro pode fazer existir. 0 mal entendido promissor, em outros termos, é uma proposição que, da maneira pela qual ela se propõe, cria a ocasião para uma nova versão possível do acontecimento.

Um encontro vivido, nesta trajetória de pesquisa, colocou-se como mal-entendido promissor, deslocando sentidos e multiplicando possibilidades na construção deste trabalho. No Encontro Nacional da ABRAPSO (Associação Brasileira de Psicologia Social), realizado em 2011, apresentamos uma versão preliminar ${ }^{3}$ desta pesquisa. Eventos como este são fecundos ao gerarem encontros e desencontros a partir do que falamos, ouvimos, silenciamos e, sobretudo, de como nossos pares nos ouvem e interpelam.

Após a rodada de apresentações, abriu-se o debate e recebemos um interessante comentário - "quase encomenda" - de um colega: frente à crise vivida pelas Organizações da Sociedade Civil e movimentos sociais, por que não fazíamos um "catálogo" classificando as ONGs "sérias" e "não sérias" para que pudesse ser utilizado e consultado por todos e, assim, solucionasse o "problema"?

A riqueza desta sugestão, pelo próprio incômodo gerado, inspirou o início da formulação deste trabalho, reforçando opções. Começando do final, ousamos afirmar que não ansiávamos por solucionar problemas ou estabelecer verdades conclusivas sobre as questões colocadas. Como uma aposta, aproximamo-nos, ao contrário, da busca por construir conhecimentos, reconhecendo-os como parciais, incompletos e provisórios.

Assim, a própria construção de nosso objeto de investigação inspirouse nesta perspectiva, transitando entre controvérsias e dissensos. A partir da noção de campo-tema - aqui entendida não como o lugar no qual se vão levantar os dados de pesquisa sobre determinado assunto, mas como campo-tema ${ }^{4}$, tal qual proposto por Spink (2003, p.19) como

"as redes de causalidade intersubjetiva que se interconectam em vozes, lugares e momentos diferentes, que não são necessariamente conhecidos uns dos outros. [...] é um tumulto conflituoso de argumentos parciais, de artefatos e materialidades"

Buscamos ampliar os modos de pensar a produção de conhecimentos, desnaturalizando nossos objetos de estudo e aproximando-nos da possibilidade de acompanhar os processos de sua construção, de modo situado. 
Assim, olhar as experiências e o modo como cada ator concede sentido aos seus saberes e fazeres possibilitou o trânsito fluido entre conceitos polifônicos e experiências múltiplas. A partir da possibilidade de pensar outras formas de construção de conhecimento, passamos a problematizar terminologias, conceitos, referenciais e práticas distintas, presentes no cotidiano de Organizações da Sociedade Civil, Organizações Não-governamentais, Terceiro Setor, etc.

Evocamos aqui o reconhecimento destas práticas não como algo dado, mas sim como construção a partir de relações heterogêneas. Trabalhar com uma visão de mundo múltiplo, heterogêneo e fluido implica na busca por outras formas de conhecê-lo, não mais a partir da estabilidade e homogeneidade. Implica ainda no reconhecimento de que existem versões da realidade e que, quando pesquisamos, detectamos, ampliamos e produzimos algumas destas versões.

Importante, neste ponto, retomar a diferenciação proposta por Mol (2007) entre perspectivismo e construtivismo, pluralismo e multiplicidade. Estas noções trazem, em sua base, o questionamento da verdade como algo inabalável, mas com diferenças cruciais. O perspectivismo não coloca em xeque a ideia de realidade. Esta está dada e pode ser acessada em sua "essência". Multiplicam-se apenas as possibilidades de olhares e abordagens. A célebre parábola dos "cegos e o elefante" é um ícone para entendermos esta proposta: cada qual, à sua maneira, toca e descreve o que está sendo percebido. O objeto está mantido intacto, sendo "visto" e representado de formas distintas. Nas palavras de Mol, "questionouse a verdade, mas não se multiplicou a realidade" (Mol, 2007, p. 4).

As propostas construtivistas igualmente tornariam, segundo a autora, o mundo mais plural. Trata-se de reconhecer que as versões dos fatos tal qual lidamos hoje são fruto de contingências históricosociais. Não estão dadas "na natureza", mas foram construídas de uma forma em detrimento de outras possíveis. Assim, para Mol, perspectivismo e construtivismo são modos plurais de pensar a produção de conhecimento. A autora, no entanto, nos convida a ir mais além, na direção de uma outra abordagem que nos aproxima das noções de multiplicidade, versão e performance.

Falar da realidade como múltipla depende de outro conjunto de metáforas. Não as de perspectiva e construção, mas sim as de intervenção e performance. Estas sugerem uma realidade que é feita e performada [enacted], e não tanto observada. Em lugar de ser vista por uma diversidade de olhos, mantendo-se intocada no centro, a realidade é manipulada por meio de vários instrumentos, no curso de uma série de diferentes práticas. Aqui é cortada a bisturi; ali está a ser bombardeada com ultrassons; acolá será colocada numa balança e pesada. 
Mas, enquanto parte de actividades tão diferentes, o objeto em causa varia de um estádio para o outro. Aqui é um objeto carnudo, ali é um objecto espesso e opaco, além é um objecto pesado. Nas histórias de performance, a carnalidade, a opacidade e o peso não são atributos de um objecto único com uma essência escondida. Tão pouco é função dos instrumentos pô-los à mostra como se fossem vários aspectos de uma realidade única. Em vez de atributos ou aspectos, são diferentes versões do objecto, versões que os instrumentos ajudam a performar [enact]. São objectos diferentes, embora relacionados entre si. São formas múltiplas da realidade - da realidade em si. (Mol, 2007, pp. 5,6)

Assim, pesquisar afasta-se da busca asséptica de representação e espelhamento da realidade e aproxima-se da intervenção, das escolhas, dos interesses. Latour (1999) fala em arregimentar aliados, robustecer argumentos; Law (2004) em agenciamentos e articulações; Mol (2007) em performatividade; Stengers (1993) em interesses.

Esta perspectiva aproxima as noções de problematização, construção de conhecimento e intervenção, situando o pesquisador como alguém que intervém sempre, fazendo escolhas e performando realidades. Não há mundo lá fora ou objeto a ser conhecido, mas um mundo que se faz o tempo todo -- e é performado ao mesmo tempo em que é conhecido. As intervenções e escolhas realizadas são inspiradas e construídas no próprio ato de pesquisar o que faz com que a pesquisa se distancie de um suposto desvelamento ou revelação de uma realidade dada a priori e se aproxime da ideia de que nossos campos de investigação se configuram ao mesmo tempo em que nós entramos em contato com ele.

Em nossa trajetória, percebemos que nosso campo de investigação se configurava nos encontros e desencontros, nos bem-ditos e nos malditos, nos bem-entendidos e nos mal-entendidos que prometiam e amplificavam vozes. A noção de mal entendido promissor passou então a nos acompanhar ao longo de toda a pesquisa.

Durante esta construção, chegamos a discutir se não seria o caso de delimitar, com maior precisão, o universo a ser analisado. Mas optamos por seguir os atores, conforme sugere Latour (2005), configurando no campo, estas fronteiras, ousando trabalhar com o social como aquilo que se configura e se desfaz, a cada espaçotempo. Para Latour,

Quando se toma [o social] como sólido, ele perde sua capacidade de se associar; quando se toma como fluido, o social novamente desaparece porque fulgura apenas brevemente, apenas no momento em que as novas associações 
mantêm o coletivo junto. [...] Ele é traçável apenas quando está sendo modificado. (2005, p. 227)

Assim, esta pesquisa colocou-se também como uma construção que requereu e possibilitou nos deslocarmos de certo modo moderno de conhecer. Para isso, foi necessário e preciso acolher a imprecisão, abrir-se à desestabilização, não ter pressa nem esperar encontrar harmonias ou generalizações, origem primeira ou "final feliz" das histórias narradas.

\section{A cartografia como caminho para outras formas de conhecer}

Santos (2006) analisa que a ciência moderna "propôs-se não apenas compreender o mundo ou explicá-lo, mas, também, transformá-lo. Contudo, paradoxalmente, para maximizar a sua capacidade de transformar o mundo, pretendeu-se imune às transformações do mundo" (p.18). Assim, completa o autor, a ciência moderna pressuporia que, ao mesmo tempo em que ela é feita no mundo, não seria feita de mundo.

O trabalho da ciência seria o de descrever ou retratar uma realidade "lá fora" que existiria independente de nossa vontade, pesquisa ou ação. O ideal desta forma de pensar o conhecimento científico é aproximar-se, o máximo possível, da verdadeira e fiel representação da realidade.

Nas palavras de Albuquerque (2007, p.22),

Bruno Latour e Michel Foucault nos falam que esta separação ou distinção radical entre o mundo das coisas e o mundo das representações, entre a natureza e a cultura, entre o que seria material e objetivo e o que seria simbólico e subjetivo, entre a coisa em si e a construção social do conhecimento, entre o objeto e o sujeito é um produto da sociedade moderna e um dos seus pressupostos fundamentais (...) O procedimento científico no ocidente moderno se caracterizaria por esta prática de purificação, pela rejeição de aceitar as misturas, as relações, as superposições, as mestiçagens.

Assim, "em nome da ciência", desde o século XIX, temos buscado submeter o mundo a uma ordem simples, estável, racional e linear, alerta Stengers (1990). E, para isso, o pesquisador e seu trabalho ficam silenciados ou invisíveis.

Law (2004), em seu "After the method: mess in social science research", reflete sobre o que temos feito quando, em nossos campos de pesquisa, lidamos com realidades múltiplas, híbridas e heterogêneas, como é o caso da abordagem que buscamos aqui 
imprimir às práticas das Organizações da Sociedade Civil. O autor afirma que faz parte do próprio realismo euro-americano - como denomina o paradigma moderno - excluir tudo que se coloca como confuso, inesperado, ou fora da ordem.

Moraes (2010), analisando a obra do autor, explica:

Presença diz respeito ao que comparece em nossos relatos de pesquisa. Ausência é aquilo que, mesmo não estando de fato presente, é um pano de fundo, uma copresença. E alteridade, ou alterização, é o que é tornado outro, excluído, deixado de fora. O manejo da presença, da ausência e da alterização faz toda a diferença. O que deixamos de fora dos nossos relatos? Por que o fazemos? O que incluímos? Por que incluímos em nossos textos estes e não aqueles relatos? Para Law (2004), tais perguntas são capitais nos debates sobre método. (Moraes, 2010, pp. 33, 34).

Problematizar a construção do conhecimento aproxima-nos, especialmente, do debate metodológico não com vistas ao estabelecimento de um "como fazer", mas como possibilidade de colocar em questão "como as coisas são feitas". Latour (1999), ao propor uma etnografia do trabalho dos cientistas, sugere seguirmos os atores aí envolvidos, começando "pela porta de trás, a da ciência em construção, e não pela entrada mais grandiosa da ciência acabada." (Latour, 1999, p.17).

A ciência, para o autor, seria como o deus Janus e teria duas faces: uma conhecida, acabada e outra em construção. Geralmente, lidamos com a "ciência pronta", isto é, com conhecimentos que nos chegam como verdades estabilizadas e hegemônicas, sem que questionemos as circunstâncias de produção dos fatos científicos, pois estas, na "ciência pronta", são apagadas e tomadas como algo dado, natural. Para isso, Latour (1999) nos convida a abrir as "caixas-pretas" e olhar as controvérsias como estratégia para nos aproximarmos de determinado campo-tema.

Neste percurso, quando somos

confrontados com uma caixa-preta, tomamos uma série de decisões. Pegamos? Rejeitamos? Reabrimos? Largamos por falta de interesse? Robustecemos a caixa-preta apropriandonos dela sem discutir? Ou vamos transformá-la de tal modo que deixará de ser reconhecível? É isso o que acontece com as afirmações dos outros em nossas mãos, e com as nossas afirmações nas mãos dos outros. Em suma, a construção de fatos e máquinas é um processo coletivo. (Latour, 1999, p.53) 
O que estes autores buscam explicitar é, dentre outros aspectos, que o critério de cientificidade designa sempre uma coletividade que transforma ficção em fatos científicos. O trabalho da ciência, como argumentam, retiraria a história de seus objetos, apagando este longo processo de estabilização. E, embora não nos caiba, neste momento, aprofundar a discussão sobre a ciência, gostaríamos de ressaltar um aspecto que faz ressonância com nossas reflexões: 0 reconhecimento da realidade não como algo dado, mas sim como construção a partir de relações heterogêneas. Trabalhar com uma visão de mundo múltiplo, heterogêneo e fluido implica na busca por outras formas de conhecê-lo, não mais a partir da estabilidade e homogeneidade. Implica ainda no reconhecimento de que existem versões da realidade e que, quando pesquisamos, detectamos, ampliamos e produzimos algumas destas versões.

A cartografia (Passos, Kastrup, \& Escóssia, 2010) insere-se neste debate, não como um conjunto de regras e procedimentos, mas antes como uma forma de olhar e intervir no campo de investigação. Trata-se de uma estratégia teórico-metodológica tenaz para a abordagem de processos que nos aproxima do vivido.

Com esta perspectiva, afastamo-nos do modo moderno de pensar a produção de conhecimentos ao rejeitar a visão de que este representaria uma realidade "lá fora". Aproximamo-nos, ao contrário, da possibilidade de acompanhar percursos, elos e conexões, entendendo que ao mesmo tempo em que pesquisamos e narramos nossos campos de pesquisa, problematizamos e produzimos realidades e subjetividades.

Conforme sinalizam Barros \& Kastrup (2010, p.57),

Diferente do método da ciência moderna, a cartografia não visa isolar o objeto de suas articulações históricas nem de suas conexões com o mundo. Ao contrário, o objetivo da cartografia é justamente desenhar a rede de forças à qual o objeto ou fenômeno em questão se encontra conectado, dando conta de suas modulações e de seu movimento permanente.

Neste sentido, cada cartografia é única e cada campo-tema (Spink, 2003, p.19) potencializa múltiplas possibilidades de cartografias. Como um ensaio, o conhecimento que se quer construir reconhece e parte das controvérsias, incertezas e ambivalências vendo-as não como estágios a serem neutralizados, ultrapassados ou purificados (Latour, 1994), mas matéria-prima de toda problematização. É preciso ressaltar, como assinala Pedro (2003, p.15), que

O conhecimento não deveria ser entendido apenas como o que busca apreender o que o mundo é, mas, sobretudo, o que produz o mundo (...). Assim, redes devem ser tomadas como 
ferramentas estratégicas, nas quais se buscam não apenas os movimentos já constituídos, mas antes, os fluxos em constituição, em que nossas próprias ações criam conhecimento, criam redes, criam mundo.

Assim, a opção metodológica não fala de um simples "como fazer", mas assenta-se e encerra uma Política Ontológica (Mol, 2007), ao reconhecer que "a atividade do pesquisador é simultaneamente epistemológica, política e ética" (Pedro, 2010, p.93).

Com Latour $(2005,1994)$, buscamos colocar as grandes categorias analíticas em suspeição, aproximando-nos de uma visão da realidade como um fluxo de relações heterogêneas entre elementos justapostos. Assim o social deixa de estar inserido para explicar a realidade e passa a ser visto como um resultado - sempre parcial e provisório - de processos de agenciamentos entre humanos e nãohumanos que se faz o tempo todo.

Nas palavras do autor (Latour, 2005, p.6, grifos nossos),

Em cada momento, temos de reconstruir a concepção do que estava associado porque a anterior definição passou a ser, até certo ponto, irrelevante. Já nem sequer estamos mais certos do que significa 'nós'; parece que somos sustentados por 'laços' que já não assemelham aos laços sociais regulares (...) Portanto, o projeto global daquilo que supostamente fazemos em conjunto é colocado em dúvida. O sentido de pertença entrou em crise. É justamente para dar conta deste sentimento de crise e para seguir estas novas conexões que nos será necessário uma outra concepção do social. Com efeito, será necessário que esta seja muito mais ampla do que comumente se designa por este termo, e todavia estritamente limitada no que respeita ao delinear das novas associações e à arquitetura criada pelos seus agregados. Eis a razão pela qual irei definir o social não já como um domínio especial, uma realidade específica ou uma coisa particular, mas apenas como um movimento muito particular de re-associação ou de reagrupamento.

Frente a uma Sociologia do Social, o autor propõe uma Sociologia das Associações para estudar os fenômenos em movimento, em constituição, antes de se estabilizarem. O trabalho de investigação a ser feito implica em seguir as configurações provisórias da realidade, sem buscar generalizações, mas nas pequenas narrativas.

Neste sentido, inspirados no trabalho realizado por Latour, em sua cartografia da ciência, buscamos tecer uma cartografia do trabalho das OSC, "entrando pela porta de trás", como sugere o autor, isto é, pelos vestígios que apontam como são construídas em seu dia a dia e 
não em seu caráter definitivo ou institucionalizado, o que implica olhar as práticas e seguir os atores, acompanhando as discussões, incertezas e embates em jogo.

A metáfora da caixa-preta talvez seja pertinente para pensarmos a constituição das OSC, sendo utilizada

na sociologia das ciências para falar de um fato ou de um artefato técnico bem estabelecido. Significa que ele não é mais objeto de controvérsia, de interrogação nem de dúvidas, mas que é tido como um dado (...). Quando uma técnica ainda não está completamente estabelecida como caixa-preta, falamos de caixa cinza (Latour) ou caixa translúcida (Jordan e Lynch). (Vinck, 1995 como citado em Pedro, 2010, p.87).

Pedro (2010, p.87) nos ajuda ainda nessa argumentação afirmando que

de modo simples, pode-se definir controvérsia como um debate (ou uma polêmica) que tem por 'objeto' conhecimentos científicos ou técnicos que ainda não estão totalmente consagrados. Isto significa que os objetos privilegiados de tais análises são as chamadas 'caixas-cinza', ou seja, questões de pesquisa que ainda portam em si controvérsias, interrogações, que ainda não se constituíram em uma 'caixa-preta'.

Seguimos assim, nossa viagem: se inicialmente buscamos configurar nosso campo-tema; agora, damos mais um passo, aproximando-nos da possibilidade de abrir esta caixa-preta. Mobilizados pelas transformações nas práticas das Organizações da Sociedade Civil, tomamo-las como "caixas-cinza", portadoras de controvérsias e interrogações, problematizando o papel e atuação destas ações hoje. $\mathrm{Na}$ mala de viagem, trazemos um "equipamento minimalista", pois, conforme salienta Pedro (2010, p.89, grifos nossos),

o ofício do cartógrafo envolve, assim, uma implicação nas redes que ele cartografa, um entendimento sem exterioridade de seus movimentos e desvios. Para tanto, lhe é conveniente um equipamento bastante 'minimalista': ao invés de um 'protocolo normalizado', o cartógrafo leva no bolso 'um critério, uma regra e um breve roteiro de preocupações', este último sempre aberto a redefinições (Rolnik, 2007, p. 67).

Seguindo suas recomendações, tomamos como porta de entrada nesta rede a experiência da OSC Espaço Compartilharte, não como um estudo de caso, mas como campo de dispersão, a partir do qual cartografamos controvérsias e possibilidades de reinvenção dos 
modos de atuação da sociedade civil no fortalecimento da democracia.

Buscamos ainda acompanhar as sinalizações de Rolnik (2007, p.66) ao nos advertir que

Um cartógrafo deve mergulhar nas intensidades de seu tempo e estar atento às linguagens que encontra, para incorporar, na composição das cartografias, todos os elementos que se fazem necessários. O cartógrafo absorve matérias de qualquer procedência. Não tem 0 menor racismo de frequência, linguagem ou estilo. Tudo o que der língua para os movimentos do desejo, tudo o que servir para cunhar matéria de expressão e criar sentido, para ele é bem-vindo. Todas as entradas são boas, desde que as saídas sejam múltiplas. O problema, para o cartógrafo, não é o do falso-ou-verdadeiro, nem o do teóricoou-empírico, mas sim o do vitalizante-ou-destrutivo ativo-oureativo. O que ele quer é participar, embarcar na constituição de territórios existenciais, constituição de realidade.

\section{Considerações finais}

Concluímos este trabalho com a expectativa de ter podido compartilhar algumas das reflexões possibilitadas em nossa experiência de pesquisa, em que a produção de conhecimento emergiu como processo-intervenção de construção de mundos possíveis que se fazem o tempo todo nas práticas.

Argumentamos que as possibilidades metodológicas abertas pela cartografia de controvérsias (Latour, 2005) nos permitem, por um lado, acompanhar a gênese das práticas, superando visões dicotômicas que nos impedem de transitar entre extremos aparentemente antagônicos; por outro, um interessante diagnóstico dos tempos atuais, no qual é preciso reconhecer sua provisoriedade, parcialidade e incompletude. E, por fim, é a potência ontológica das controvérsias que sustenta nossa aposta em um futuro possível, tanto mais criativo quanto conseguirmos construir certas mestiçagens e práticas híbridas - e em relação ao qual abrem-se lacunas, novas perguntas e desafios.

A opção pela cartografia como caminho metodológico implica que qualquer texto é um mapa possível dentre tantos outros. É, portanto, limitado, parcial, provisório. Implica, sobretudo, os desafios de uma escrita sobre realidades que se fazem ao mesmo tempo em que buscamos conhecê-las. Mais ainda: implica o pesquisador em um conhecer-fazer em que, também ele, é actante. Trata-se, portanto, não mais de epistemologias, mas de políticas de pesquisa, onde pesquisar envolve fazer existir, no texto, um mundo comum. 
Uma construção como esta não pede fechamento. Uma cartografia de controvérsias não busca sínteses ou generalizações. O êxito deste texto tecido dá-se pela possibilidade de multiplicar cenas, leituras, conexões e versões - e a aposta de que venham outras leituras, outras cartografias, outras redes e mapas para continuar compartilhando destinos.

\section{Referências}

Albuquerque, D. (2007). História. A arte de inventar o passado. Bauru, SP: EDUSC.

Barros, L., \& Kastrup, V. (2010) Cartografar é acompanhar processos In E. Passos, V. Kastrup, \& L. Escóssia (Orgs.) Pistas do método da cartografia: Pesquisa-intervenção e produção de subjetividade (pp. 52-75). Porto Alegre: Sulina.

Despret, V. (1999). Ces émotions qui nous fabriquent: ethnopsychologie de l'authenticité. Paris: Les Empêcheurs de Penser en Rond/Le Seuil.

Latour, B. (1999). Ciência em ação: como seguir cientistas e engenheiros sociedade afora. São Paulo: UNESP.

Latour, B. (1994). Jamais fomos modernos. Rio de Janeiro: Editora 34.

Latour, B. (2004). Se falássemos um pouco de política? Política \& Sociedade: Revista de Sociologia Política, (4), 11-41.

Latour, B. (2005). Reensamblar lo social - Una introducción a la teoría del actor-red. Buenos Aires: Ediciones Manatial.

Law, J. (2004). After method: mess in social science research. London; New York: Routledge.

Mol, A. (2007). A Política ontológica: algumas ideias e várias perguntas. In J. Nunes, \& R. Roque (Orgs.). Objetos impuros experiências em Estudos Sociais da Ciência (pp. 63-78). Porto: Edições Afrontamento.

Moraes, M. (2010). PesquisarCOM: Política ontológica e deficiência visual. In M. Moraes \& V. Kastrup (Orgs.) Exercícios de ver e não ver: arte e pesquisa com pessoas com deficiência visual (pp. 26-51). Rio de Janeiro: Nau.

Moraes, M., \& Kastrup, V. (2010). Exercícios de ver e não ver: arte e pesquisa com pessoas com deficiência visual. Rio de Janeiro: Nau.

Moreira, M. (2014). O que foi feito, amigo, de tudo que a gente sonhou? Uma cartografia da atuação de Organizações da Sociedade Civil no fortalecimento da democracia. Tese de doutorado, Universidade Federal do Rio de Janeiro, Rio de Janeiro, RJ, Brasil. 
Nogueira, M. A. (2011). Um estado para a sociedade civil. Temas éticos e políticos da gestão democrática. São Paulo: Cortez.

Passos, E., Kastrup, V., \& Escóssia, L. (2010). Pistas do método da cartografia: Pesquisa-intervenção e produção de subjetividade. Porto Alegre: Sulina.

Pedro, R. M. L. R. (2003). As redes na atualidade: refletindo sobre a produção de conhecimento. In M. D’Ávila, \& R. Pedro (Orgs.). Tecendo o desenvolvimento (pp. 29-47). Rio de Janeiro: MAUAD.

Pedro, R. M. L. R. (2010). Sobre redes e controvérsias: ferramentas para compor cartografias psicossociais. In A. A. L. Ferreira, L. L. Freire, M. Moraes \& R. J. J. Arendt (Orgs). Teoria Ator-Rede e Psicologia. (pp. 78-96). Rio de Janeiro: Nau.

Pedro, R. M. L. R., \& Moreira, M. C. (2013) Da utopia à construção de práticas psicológicas no campo da assistência social ou da psicologia no encontro com o outro. In L. R. Cruz, L. Rodrigues, $\&$ N. M. F. Guareschi (Orgs.). Interlocuções entre a psicologia e a política nacional de assistência social (pp. 69-77). Santa Cruz do Sul: UNISC.

Rolnik, S. (2007). Cartografia sentimental - transformações contemporâneas do desejo. Porto Alegre: Sulina/Editora da UFRGS.

Santos, B. S. (2006). Conhecimento prudente para uma vida decente: um discurso sobre as ciências revisitado. São Paulo: Cortez.

Spink, P.K. (2003) Pesquisa de campo de psicologia social: uma perspectiva pós-construcionista. Psicologia \& Sociedade, 15(2), $18-42$.

Stengers, I. (1990) Quem tem medo da ciência? Ciência e poderes. São Paulo: Siciliano.

Stengers, I. (1993). L'invention des sciences modernes. Paris: La Decouverte.

Venturini, T. (2010). Diving in Magma: How to Explore Controversies with Actor-Network Theory. Public Understanding of Science, 19 3, 258-273.

\section{Endereço para correspondência \\ Rosa Maria Leite Ribeiro Pedro}

Universidade Federal do Rio de Janeiro

Instituto de Psicologia - Programa de Pós-Graduação em Psicologia

Av. Pasteur, 250, Pavilhão Nilton Campos, Praia Vermelha, CEP 22290-240, Rio de Janeiro - RJ, Brasil

Endereço para correspondência: rosapedro@globo.com

\section{Mariana de Castro Moreira}

AVM Faculdade Integrada - Rio de Janeiro, Brasil

Rua do Carmo, 07, 13ㅇandar, Centro, CEP 20011-020, Rio de Janeiro - RJ, Brasil

Endereço para correspondência: mari.moreira@oi.com.br 
Recebido em: 03/06/2014

Reformulado em: 30/09/2014

Aceito para publicação em: 15/10/2014

\section{Notas}

* Possui graduação em Psicologia pela Universidade Federal do Rio de Janeiro (1985), mestrado em Psicologia pela Fundação Getúlio Vargas - Matriz (1989) e doutorado em Comunicação pela Universidade Federal do Rio de Janeiro (1996). Atualmente é professor associado da Universidade Federal do Rio de Janeiro. Tem experiência na área de Psicologia, com ênfase em Cultura Contemporânea Subjetividade e Construção do Conhecimento, atuando principalmente nos seguintes temas: subjetividade, tecnologia, redes sócio-técnicas, sociedade contemporânea e redes.

** Possui doutorado (2014) e mestrado (2000) em Psicossociologia de Comunidades e Ecologia Social pela Universidade Federal do Rio de Janeiro (UFRJ). Especialização em Psicologia Social (Aprovada no concurso do Conselho Federal de Psicologia, 2012). Graduação em Psicologia pela UFRJ (1997). Possui experiência docente no Ensino Superior desde 1999 e em pesquisa desde 1994. Atualmente, trabalha como professora, pesquisadora e coordenadora de cursos de graduação e pós-graduação presencial e à distância. Áreas de atuação: Educação e Gestão; Movimentos Sociais, Organizações da Sociedade Civil e Políticas Públicas; Produção de Conhecimentos e Metodologia da Pesquisa. Possui experiência na gestão de projetos sociais e educativos junto a Organizações da Sociedade Civil desde 1991. Participou de diversos conselhos formuladores de Políticas Públicas. É autora de artigos e livros publicados nas áreas de atuação.

${ }^{1}$ Cf. MOreira, M. C. (2014).

${ }^{2} \mathrm{Na}$ obra de Foucault, encontramos o conceito de dispositivo como "um conjunto decididamente heterogêneo que engloba discursos, instituições, organizações arquitetônicas, decisões regulamentares, leis, medidas administrativas, enunciados científicos, proposições filosóficas, morais, filantrópicas. Em suma, o dito e o não dito são os elementos do dispositivo. O dispositivo é a rede que se pode tecer entre estes elementos" (Foucault, 1979, p. 244).

${ }^{3}$ Apresentação oral realizada no 16을 Encontro Nacional da Associação Brasileira de Psicologia Social (ABRAPSO), realizado entre os dias 12 e 15 de novembro de 2011, em Recife - PE.

${ }^{4}$ Vale aqui registrar um agradecimento aos professores que participaram de nosso Exame de Qualificação de Pesquisa de Tese, pelas contribuições e sugestões, dentre estas a noção de campo-tema. 